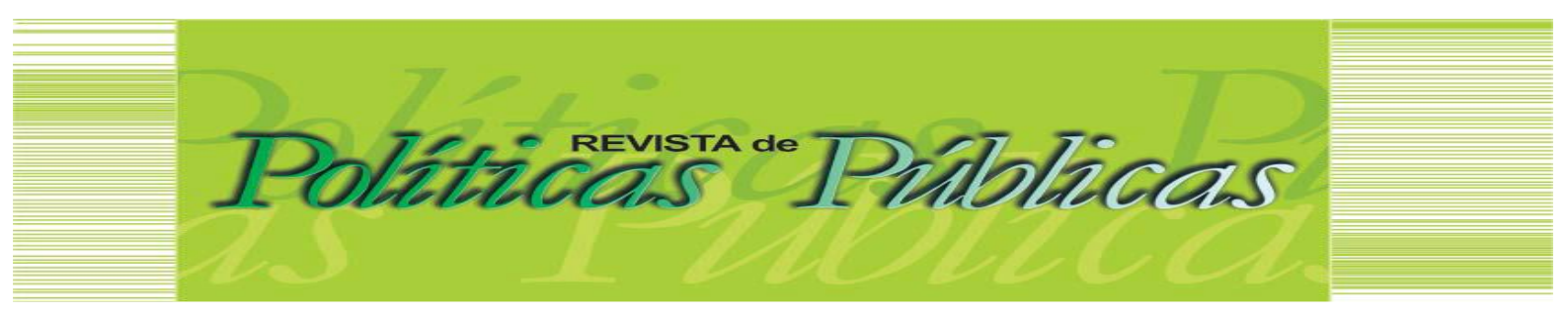

\title{
A FARDA E A INTIMIDADE: novos desafios da feminização das Forças Armadas Brasileira
}

\author{
Nilza Rogéria de Andrade Nunes ${ }^{1}$ \\ Nádia Xavier Moreira ${ }^{2}$
}

\begin{abstract}
Resumo
Este artigo reflete como os valores militares da hierarquia e da disciplina se fazem presentes na interação dos casais de dupla-carreira nesse ambiente. A presença do efetivo feminino nas Forças Armadas Brasileira possibilitou relações diferenciadas pela estrutura militar, em sua dimensão afetiva, amorosa e sexual. Através de produções bibliográficas e observação participante, evidenciamos que o namoro e o casamento entre militares de diferentes escalões subvertem, na prática, as distâncias, sobretudo entre o círculo de praças e oficiais e abriram a possibilidade de desenrijecimento das diferenças hierárquicas, aspecto que impõe desafios à conciliação família-trabalho nesse ambiente.
\end{abstract}

Palavras-chave: família; casamento; gênero; Forças Armadas Brasileira.

THE UNIFORM AND THE INTIMACY: new challenges of the feminization of the Brazilian Armed Forces

\begin{abstract}
This article reflects how the military values of hierarchy and discipline are present in the interaction of dual-career couples in this environment. The presence of the female force in the Brazilian Armed Forces allowed differentiated relations for the military structure, in its affective, loving and sexual dimension. Through bibliographical productions and participant observation, we have shown that courtship and marriage between military personnel of different echelons distort, in practice, the distances, especially between the circle of squares and officers, and opened the possibility of the dissolution of hierarchical differences, an aspect that imposes challenges to family-work reconciliation in this environment.

Keywords: Family; Marriage; Gender; Brazilian Armed Forces

Artigo recebido em: 08/10/2018 Aprovado em: 06/04/2019. DOI: http://dx.doi.org/10.18764/2178-2865.v23n1p11-26.
\end{abstract}

\footnotetext{
${ }_{1}^{1}$ Assistente Social. Doutora em Serviço Social pela PUC-RJ com estágio doutoral pela CAPES na Universidade de Dundee - Escócia. Professora convidada da Pós-Graduação em Psicopedagogia do Instituto Superior de Educação Pró-Saber ISEPS. Professora de Pós-Graduação, Graduação e Extensão do Departamento de Serviço Social da Pontifícia Universidade Católica do Rio de Janeiro (PUC-RJ). Endereço: R. Marquês de São Vicente, 225 - Gávea, Rio de Janeiro RJ. CEP: 22451-900. Email: n.rogerianunes@gmail.com

2 Assistente Social. Doutora em Serviço Social pela Universidade Federal do Rio de Janeiro (UFRJ). Trabalha na Marinha do Brasil. Endereço: End. Prof.: Praça Barão de Ladário, s/n, $5^{\circ}$ andar- Centro-RJ. CEP: 20091-00
} 


\section{INTRODUÇÃO}

O estudo da família, como um todo, e dos casais, em particular, tem experimentado grandes mudanças. Os métodos de pesquisa e as abordagens teóricas vêm buscando refletir e se adaptar à complexidade do tema. No ambiente militar essas questões se fazem presentes sob a égide da hierarquia e da disciplina, determinantes no comportamento de homens e mulheres e que trazem, em si, um conjunto de valores e atitudes que implicam na própria identidade militar. Assim, buscamos refletir sobre possiveis impactos que a farda exerce na família e no trabalho diante da emergência de uma nova possibilidade relacional na qual os valores do militarismo transcendem os muros dos quartéis e invadem a intimidade de seus membros.

Os casais em que ambos trabalham em tempo integral, nomeados dupla-carreira, no ambiente militar somente tornou-se possível com a entrada de mulheres nas Forças Armadas. Pois, 0 processo de recrutamento feminino nos países ocidentais, a partir dos anos 70, fez-se acompanhar não somente por significativas transformações nas condições de exercício da violência organizada e na própria estrutura organizativa das instituições militares, mas também repercutiu nas relações cotidianas de seus membros.

Um estudo clássico realizado por Janowitz (1967) mostra como se constitui a profissão militar, qual 0 ethos que a sustenta. Segundo 0 autor, para tornar-se um profissional das armas, 0 soldado deve deixar de ser o indivíduo que é e transformar-se num ser cuja identidade é determinada pela instituição, que tem como função o combate. Todo aprendizado do soldado tem como finalidade construir um novo homem. 0 elemento central desta identidade é justamente a masculinidade, pois a guerra sempre foi associada à agressão. Para 0 autor, as Forças Armadas talvez sejam a mais masculina de todas as instituições sociais, bem como uma das mais fechadas e conservadoras; aliás, a conservação é típica da profissão militar, pois cabe a ela garantir a permanência do Estado.

Ao longo da nossa trajetória no exercício superior, trabalhando com questões de poder, gênero e família e como assistente social militar, identificamos empiricamente, através de escutas e conversas com colegas de farda, da observação de posicionamento de comandantes, bem como por meio da observação participante no exercício profissional com o atendimento a casais, que em muitas ocasiões, o casamento entre militares, quando não bem administrado pelos cônjuges, pode vir a se constituir em fonte de estresse e de transtornos familiares e profissionais.

Notamos ainda que em muitas ocasiões o casamento entre praças e oficiais ${ }^{1}$ não é visto como algo comum na instituição. É encarado, em diversas situações, como quebra de hierarquia. Observamos ainda que tal questão ganha contornos mais complexos quando neste tipo de casamento 0 oficial é uma mulher. 
Questões gerais que nos ocorriam nessas ocasiões e que nos motivaram a refletir sobre 0 tema: quais os principais problemas conjugais enfrentados por casais militares decorrentes do ambiente de trabalho, advindos de sua posição hierárquica? Como analisam que esses problemas influenciam na qualidade do seu casamento? Como se sentem os homens, quando são praças casados com mulheres oficiais, nesta posição de suposta dupla subalternização: econômica e hierárquica? Como a instituição se posiciona de modo velado e formal sobre o casamento entre pares? Questionamentos tangenciados pelas relações de gênero e poder no trabalho e na intimidade.

O tema possui relevância social porque com o crescimento da participação feminina na força de trabalho, o casamento de duplo-trabalho será uma realidade cada vez mais presente na família, tornando-se regra ao invés de exceção. No tocante ao casamento de dupla-carreira, pesquisas apontam que os conflitos entre casamento e trabalho são mais agudos nesse tipo de casal: as mulheres padecem de fragmentação de identidade, elevado nível de estresse, sentimento de culpa; os homens, do desgaste gerado na relação conjugal por conta da administração de vários contextos de atuação. (MARTINS, 2006).

Tomando a contribuição de lamamoto (1999), é possível se dizer que o conhecimento constitui para o profissional de serviço social um recurso essencial no exercício do seu trabalho, um meio pelo qual é possível decifrar a realidade e clarear a condução da sua prática interventiva. Em sintonia com o projeto ético-político profissional, assistentes sociais precisam estar preparados para acolher as queixas, demandas da díade e a riqueza relacional, decorrentes deste estilo de vida, a fim de oferecer uma intervenção técnica mais qualificada, com vistas a propor políticas e ações no âmbito institucional que contribuam com respostas aos dilemas enfrentados por esses casais nessa esfera. Os profissionais ainda não estão habilitados para lidar com esta nova realidade, na qual os casais que trabalham fora ocupam cada vez mais setores da sociedade, devendo tornar-se, em tempo cada vez menor, modelos predominantes em comparação com casais de renda única.

\section{NOVOS TEMPOS E AS TRANSFORMAÇÕES NA FAMÍLIA E NO CASAMENTO}

As questões trazidas por este estudo encontram-se diretamente ligadas às transformações vivenciadas pela família nas últimas décadas, cujos impactos se fizeram sentir profundamente na estrutura tradicional da família patriarcal (THERBORN, 2006) ${ }^{2}$. Concepções sobre casamento, reprodução, maternidade, paternidade passaram a ser reavaliadas sob uma perspectiva de igualdade de gênero e da autonomia econômica e pessoal das mulheres.

Há consenso entre pesquisadores e estudiosos da área (PERLIN; DINIZ, 2005; DINIZ, 1993) acerca de que um dos principais deflagradores das alterações que ocorreram no âmbito familiar e no casamento foi a entrada maciça de mulheres casadas no mercado de trabalho. Essa participação 
estremeceu a divisão do trabalho socialmente estabelecida entre homens e mulheres, na qual cabia ao homem prover materialmente a família, incumbido com o mundo externo ao lar; nesse contexto, a mulher era a responsável pela administração do mundo interno: cuidava da casa, da educação dos filhos, era também a provedora afetiva do marido e filhos. Acerto que é de certo modo solapado com o engajamento da força de trabalho feminina no mundo do trabalho.

Em decorrência desse processo, os espaços de domínio de cada um - homem e mulherpassam a ser questionados e novos arranjos e reformulações nas funções conjugais são mobilizados. Dessa forma, o casamento contemporâneo encontra-se formatado em estilo relacional muito distinto daquele existente no início do século passado. Diferentemente de suas origens, onde se casava por interesses políticos e econômicos (GIDDENS, 1993; ARIĖS, 1978), atualmente se casa principalmente por razões afetivas e sexuais.

Nessa perspectiva, observa-se que o estilo de vida contemporâneo coloca exigências ambivalentes para o casamento (JABLONSKI, 2001; PERLIN; DINIZ, 2005): presenciam-se, concomitantemente, pressões para manutenção de valores e padrões tradicionais como a monogamia, modelos tradicionais de sexualidade, de divisão de papéis e funções de família de acordo com sexo, tendo de conviver com as exigências de adequação às transformações sociais que estimulam um gozo maior da sexualidade, a valorização do crescimento pessoal, sob um enfoque individual, da independência financeira e da reorganização e flexibilização no exercício dos papéis de gênero.

A exacerbação de demandas sociais impostas ao casal, por vezes antagônicas, tem levado a um estado de confusão de valores e de atitudes, que culmina em muitos casos de separação e divórcio. Para Rocha-Coutinho (2000), os casais findam por sentir em seu cotidiano pressões pela multiplicidade e sobrecarga de papéis impostos por um estilo de vida que busca conciliar vida pessoal, conjugal, familiar e ocupacional.

De acordo com Vaitsman (1994), a modernização promoveu um processo de individualização das famílias, ocasionando profundas mudanças na vida do casal, a conjugalidade passou a ser regulada por um novo pacto entre casais, permitindo maior horizontalidade nas relações entre os sexos e uma maior elasticidade na relação entre pais e filhos.

Com a mudança nas condições de reprodução da população e nos padrões de relacionamento entre os membros da família, com as relações de poder e autoridade sendo questionadas e, principalmente, com a inserção da mulher no mercado de trabalho, podemos observar alterações na família ao longo da história, que têm colocado em questão padrões de relações tradicionalmente difundidos, tornando cada vez mais difícil uma conceituação que dê conta dessas novas formas de se pensar a família. 
Além dos modelos nomeados de tradicionais de família, assiste-se ao surgimento de novos arranjos familiares, muito em função da liberalização feminina, a saber: famílias com base em uniões livres, sem casamento civil ou religioso; famílias mono parentais, na maioria chefiada por mulheres; aumento do número de divórcios e separações; mães adolescentes solteiras; mulheres que decidem pela produção independente, sem nenhum tipo de vínculo ou convívio com o pai da criança; famílias formadas por casais do mesmo sexo e famílias de recasados e as famílias constituídas por casais de duplo-trabalho ou dupla-carreira.

\section{QUANDO TUDO É EM DOBRO: os casais duplo-trabalho ou dupla-carreira}

No decorrer das últimas décadas, a presença em grande número de mulheres no mercado de trabalho tem vindo a alterar modos de funcionamento tanto na esfera laboral, quanto no âmbito familiar. Famílias onde somente um membro do casal trabalha fora de casa cederam espaço a famílias de duplo emprego. Tal padrão familiar recente suscitou novos desafios e mudanças nos papéis de gênero tradicionais, impondo para os casais a necessidade de conciliar tarefas profissionais com tarefas familiares.

A literatura tem denominado de casamento duplo-trabalho ou dupla-carreira aquele em que ambos os cônjuges trabalham fora em tempo integral. Para Diniz (1996), casais de dupla-carreira representam um subgrupo especial dentre os casais de duplo-trabalho. Considera família de duplacarreira aquelas em que:

\footnotetext{
Ambos os esposos exercem profissões conhecidas como "carreiras", por terem uma demarcação clara das etapas de desenvolvimento e progressão, por exigirem um alto grau de instrução e treinamento, de comprometimento com o trabalho e reciclagem constante. São também atividades cujo exercício requer investimento e interesse pessoal alto, principalmente porque as demandas do trabalho são levadas para, ou até mesmo invadem outras áreas da vida (DINIZ, 1996, p. 102).
}

Tais ofícios repercutem na estrutura familiar tradicional e torna necessária uma maior reorganização dos papéis tradicionais de gênero no contexto familiar, o que pode ser muito estressante para os casais que optam por este estilo de vida, haja vista terem que lidar com a demanda de mudança e/ou adaptações em papéis que antes eram bem delimitados.

O termo família de dupla carreira, conforme utilizado por Rapoport e Rapoport (1969), para descrever o que entendiam se constituir uma modalidade especial de família de dupla renda. Por ter emergido enquanto resposta às transformações sociais do pós-guerra, era considerada revolucionária. O caráter inovador proposto pelos cônjuges consistia na conciliação de carreiras independentes e o estabelecimento de uma vida familiar que incluísse ao menos uma criança. (MONTEIRO, 2001). Os mesmos autores conceberam que o conceito de casal de dupla carreira 
contrastava com o de outro tipo de casal para os quais a carreira não se constitui em um polo estruturante do relacionamento.

A vida do casal de dupla carreira significa, além das tarefas e responsabilidades, a administração de múltiplos papéis sociais, diferenciados entre si e modificados pelas inovações produzidas pela própria interação entre os cônjuges. Esse processo de revisão de papéis sociais afeta tanto as mulheres, que podem contar com maior participação dos homens nas tarefas domésticas, quanto os homens, por terem que se adaptar às múltiplas demandas dos papéis profissionais de suas mulheres.

Estudos sugerem que dilemas na interação família-trabalho, se não bem administrados, impactam de modo negativo não somente em vários aspectos do casamento (sexual, cuidado da casa e filhos, nível de investimento na carreira, subjetividade dos parceiros), mas suas consequências se desdobram para setores laborais e de saúde dos seus membros. (PERLIN, 2006; DINIZ, 1999; ROCHA-COUTINHO, 2003).

Apesar das dificuldades decorrentes da negociação equitativa e das modificações dos papéis sociais, esse tipo de casal encontra-se cada vez mais em evidência social e econômica. A despeito dessa realidade, os problemas advindos do casamento dupla-carreira são ainda tratados na esfera pública como uma questão de ordem privada. As instituições negam a existência de dificuldades nessa área ou mesmo a ignoram. Poucas são ainda as corporações que vêm elaborando ou mesmo adaptado sua política interna com vista a atender às necessidades dos casais nesses moldes.

As questões elencadas podem ganhar contornos mais complexos quando o casal vivencia tais dilemas nas instituições militares, calcadas na hierarquia e disciplina que têm ainda na cultura organizacional valores e significações que conformam um culto ao masculino. (CASTRO, 1990). Tornase, assim, necessário, para o melhor entendimento dos elementos da corporação que incidem sobre 0 casal dupla-carreira nesse espaço, caracterizar, ainda que de modo sumário, os aspectos que consubstanciam a forma de ser e de aparecer das instituições militares e que conformam a identidade militar.

\section{A CONSTRUÇÃO DA IDENTIDADE MILITAR NA CONFORMAÇÃO DE PRÁTICAS SOCIAIS}

Homens ou mulheres, ao ingressar em uma instituição castrense, tornam-se herdeiros de um conjunto simbólico identificador da instituição composto por práticas e discursos, expressos em cerimônias, símbolos, rituais e no dia a dia institucional. A instituição precisa ter mecanismos que possibilitem esse processo de assimilação da herança construída.

Para além das organizações e expressões concretas da presença institucional, seus prédios e suas produções materiais, a instituição se realiza no campo da subjetividade, como força de 
perpetuação de determinadas práticas. Esse mecanismo é assegurado através de um processo de socialização imposto a todos que fazem parte dos seus quadros, cuja construção social, advinda desse artifício, forme a identidade militar.

Tal construção, denominada por Castro (1990) de espírito militar, consiste no processo, experimentado pelos neófitos no ofício das armas, de socialização profissional. Essa socialização é efetivada quando os sujeitos adquirem disposições, percebidas como evidentes, naturais, predispondoos a agir de determinada maneira, sem necessidade de lembrar explicitamente das regras a serem seguidas, ou seja, quando há a incorporação do habitus militar.

Logo, a inserção na caserna impõe, àqueles que buscam a carreira das armas, abraçarem valores e princípios de visão e divisão de mundo, que resultarão na apreensão do habitus militar e na produção da filiação dos indivíduos a essa classe. Tal processo ocorre por meio de uma ação pedagógica extremamente violenta, do ponto de vista simbólico, na qual se busca matar o velho homem (BOURDIEU; PASSERON, 2012) e gerar um novo habitus, possuidor de características específicas da instituição Forças Armadas, o qual foge aos padrões usuais da sociedade civil.

Esse processo ocorre, em termos práticos, por meio de uma série de estratégias de socialização, cujo ponto principal reside na docilização dos novos membros, de forma tal que se ajustem adequadamente ao novo espaço, tornando-se úteis à manutenção da identidade e da integridade da organização.

Estudos ainda apontam que as relações sociais no campo militar são norteadas por duas categorias centrais: a hierarquia e a disciplina, as quais possuem uma relação de interdependência e são reconhecidas pela própria organização como pilares da instituição militar. (CASTRO, 1990; LEIRNER, 2006, 2009). A hierarquia constitui elemento chave para compreensão da mentalidade militar, separação entre mundo castrense e mundo civil. A disciplina norteia as condutas individuais e coletivas no campo militar; é princípio primeiro da divisão social de tarefas, papéis e status no interior das Forças Armadas, determina condutas e estrutura relações de mando e obediência.

O poder e a autoridade disciplinar são obtidos através da distribuição dos indivíduos no espaço, lançando mão, para isso, da especificação de um local, do princípio da localização imediata e funcional, e, do intercâmbio dos indivíduos; valem-se também do controle das atividades, por meio de horários, da elaboração temporal do ato, da correlação corpo-gesto, da articulação corpo-objeto e da utilização exaustiva do corpo.

$\mathrm{O}$ conjunto arquitetônico da instituição deve compor uma estrutura favorável à vigilância e à observação de todas as pessoas que transitam por ele. Os horários devem ser rigidamente cumpridos, as atividades são sistematicamente realizadas à luz de uma programação diária: alimentarse, ordem unida, assistir às aulas, realização de provas, estudos obrigatórios, etc. As tarefas são 
realizadas, na maior parte das ocasiões, comandadas por toques das cornetas, campainhas, sirenes, ordens verbais, gestos corporais, com vistas a automatizar a conduta dos discentes. Adicionam-se os mecanismos de controle, como recompensas e punições, que possibilitam assegurar respostas apropriadas aos estímulos correspondentes. Segundo Foucault (1987), a disciplina aumenta a força em termos econômicos de utilidade e diminui a resistência que o corpo pode oferecer ao poder.

Aspecto também importante à análise da instituição militar é a forte presença de ritos, pois tal espaço é marcado por um sistema de relações hipercodificadas. Prescrições, regulamentos, comandos, cerimonial e protocolos são estabeleciados não apenas para ocasiões solenes, mas ainda para atos triviais da vida dos seus membros. Sentar-se à mesa, entrar numa embarcação, participar de um evento social, falar com um superior, cumprimentar um colega, realizar uma formatura ou um funeral e combater passam pelo mesmo regime prescritivo. (LEIRNER, 2009).

Nessa perspectiva, em uma profissão em que comportamentos, atitudes e gestos são rigorosamente normatizados e supervisionados, como é o caso da profissão militar, o relacionamento íntimo entre seus membros pode sugerir que alguma regra foi infringida. (FORGEAU, 2006).

5 QUANDO AS MULHERES ENTRAM EM CENA: o processo de feminização nas forças armadas brasileiras

Segundo Lombardi (2009), a feminização, no âmbito do trabalho, constitui no processo de inserção e ampliação da presença das mulheres em ambientes de trabalho e profissões hegemonicamente masculinos. Para a autora, a perspectiva teórica subjacente à categoria analítica feminização sugere o estudo das mudanças nas relações sociais entre os sexos, nas identidades e representações profissionais e transformações institucionais de várias ordens, que costumam acompanhar a integração em profissões tradicionalmente masculinas.

0 processo de feminização das Forças Armadas brasileiras foi iniciado na Marinha em 1980, com a concepção do Corpo Auxiliar Feminino da Reserva da Marinha (CAFRM), expandindo-se a seguir pelas demais Forças Arrmadas (FFAA)3. Para Lombardi (2009), a seleção da primeira turma de mulheres oficiais, em 1981, esteve também relacionada à necessidade de suprir de mão de obra especializada o Hospital Naval Marcílio Dias (HNMD), criado também em $1980^{4}$.

A admissão de mulheres atendeu, também, a uma necessidade de liberação dos homens militares de funções burocráticas em terra para seu emprego em setores operativo (navios), ou seja, visava a utilização do "[...] trabalho feminino no desempenho de uma atividade masculina, liberando 0 militar para emprego no mar." (MARQUES; HIRON, 1982, p. 11). 
Ratificou-se, desse modo, um aspecto histórico, trabalhado por Lagrave (1995), sobre os condicionantes da inserção profissional feminina em ocupações do domínio masculino: sua efetivação, quando os homens iniciam um movimento de abandono silencioso de tais ocupações.

Contribuindo com esse debate, Chies (2010, p. 510) acrescenta que, mesmo quando homens e mulheres exercem um mesmo ofício, ocorre um processo de diferenciação das identidades profissionais segundo os gêneros, pautado nos estereótipos sociais atribuídos aos sexos, "[...] o que inevitavelmente indica que homens e mulheres não podem ter a mesma identidade mesmo que atuantes em uma mesma profissão".

As elaborações de Chies (2010) também oferecem uma contribuição bastante apropriada à análise do processo de inserção de mulheres nas Forças Armadas brasileiras na qualidade de militar. Sobre tal processo na Marinha, o estudo de Marques e Hiron (1982, p. 11) indica que foi motivado, entre outras razões, para "[...] aproveitá-las em funções que pela peculiaridade da instituição feminina, são por elas melhor realizadas, como por exemplos profissionais nutricionistas, assistentes sociais, psicólogas, enfermeiras, bibliotecárias, médicas".

Dessa forma, reproduziu-se na ocasião uma divisão sexual do trabalho ancorada em características tradicionalmente atribuídas aos papéis sociais de homens e mulheres, demarcatórias de esferas diferenciadas de atuação laboral. Partiu-se, assim, da premissa de que características biológicas (diferenciadas pelo sexo) pesam mais que a história individual de formação para o exercício de uma profissão. Nesse sentido, traz como características o que seria trabalho de mulher, competência de mulher, lugar de mulher. (BIROLI, 2018).

Foge aos objetivos deste estudo a análise das condições político-institucionais que proporcionaram condições favoráveis à presença feminina na Força Armada, notadamente na Marinha. Estudos que já trataram dessa questão (ALMEIDA, 2008; LOMBARDI, 2009) apontam que o objetivo da inserção da mulher na Marinha encontra-se relacionado ao suprimento de recursos humanos, necessários à substituição e recomplemento de funções técnicas e administrativas, desenvolvidas por praças e oficiais em terra, deslocando-os para setores operativos.

Acrescenta-se a isso a conveniência do ato, face à sua abrangência social, contribuindo para a modernização e humanização da imagem da instituição, desgastada após anos de regime militar. Esa análise é corroborada por Mathias (2009), segundo o qual, a incorporação das mulheres nas Forças Armadas, feita ao final dos regimes autoritários, teve como um dos seus propósitos sinalizar, tanto para o público interno quanto para o externo, a presença feminina nos quartéis como uma barreira para abusos cometidos por seus pares ao longo do autoritarismo e também de humanização do ambiente, dado o arbitrário cultural de que são as mulheres "[...] maternais, meigas e frágeis por definição." (MATHIAS, 2009, p. 47). 
Dentre os benefícios trazidos pela presença das mulheres nas Forças Armadas, avaliados pelos próprios militares, destaca-se um maior grau de civilidade, humanização e flexibilização nos relacionamentos interpessoais. (ALMEIDA, 2008). Desse modo, a contribuição das mulheres estaria relacionada às qualidades tidas como femininas em território predominantemente masculino.

\subsection{Encontros na intimidade: desafios dos casais dupla-carreira e o ambiente militar}

A presença do efetivo feminino na instituição militar abriu espaço à aceitação de relações diferenciadas não estruturadas pela hierarquia institucional: relações, intra e inter círculos (círculos de praças e de oficiais), em sua dimensão afetiva, amorosa, sexual.

Portanto, a inserção de mulheres na profissão militar introduziu a possibilidade de uma nova forma de interação, antes inconcebível, que consiste na experiência amorosa. Com isso, inserese um novo eixo, de natureza horizontal, nas relações interpessoais.

O namoro e o casamento de militares de diferentes graus hierárquicos subvertem, na prática, as distâncias, até então intransponíveis, sobretudo entre o círculo de praças e oficiais e abrem a possibilidade de desenrijecimento das diferenças hierárquicas.

Tais aspectos mobilizam resistências no interior da corporação, produzem desconforto e impõem desafios para os casais na conciliação família-trabalho, principalmente quando se trata de pessoas de diferentes patentes, pertencentes a círculos distintos. Afinal, mesmo fora dos quartéis, os militares estão formalmente submetidos a padrões prescritos de comportamento e aos limites impostos pelos círculos hierárquicos, regulamentadores de locais de trabalho, salas, refeitórios, banheiros, alojamentos, dentre outros aspectos. A mistura entre círculos é denominada promiscuidade hierárquica, fato bastante preocupante para a instituição, pois pode comprometer a base da hierarquia.

Outro aspecto ainda importante de se observar nessa questão é a relação peculiar existente entre família e Organização Militar. (BALTAZAR; SALVADOR, 2012; SILVA, 2013).

\footnotetext{
Enquanto no universo individualista a família é tomada como algo externo às carreiras, profissões e a uma dimensão pública da vida social, podemos notar que na vida militar a família é vista como interior à instituição. E daí o termo "Família Militar" ser frequentemente evocado pelos militares, para indicar ora o contingente militar da instituição [0 elemento "profissional"- todos os militares]; ora a família no seu sentido "privado" (cônjuge e filhos/as) e ora todos estes elementos juntos [a grande "Família Militar" - militares e seus dependentes]. (SILVA, 2013, p. 866).
}

Portanto, o habitus militar estrutura uma visão de família como autorrepresentação da instituição militar e de seus membros, incluindo-se, nesse aspecto, os cônjuges e filhos de militares, afinal a instituição busca incutir "[...] a ideia de que a instituição militar 'engloba' a família dos militares". (SILVA, 2013, p. 864), ou seja, reforça a crença de que as Forças Armadas e seu contingente fazem parte de uma mesma família, a família militar. 
Nessa perspectiva, fazendo parte de um mesmo grupo familiar, espera-se que tanto a instituição como os seus agentes socorram-se mutuamente nas ocasiões adversas. Essas situações podem se tornar recorrentes e ganhar contorno mais complexo em virtude das próprias exigências da profissão, notadamente o fato da permanente disponibilidade que devem ter os militares para o serviço, tanto em termos temporais, como em termos de mobilidade territorial.

Estudos recentes (SILVA, 2009) revelam que a própria familia militar apresenta características que a definem segundo normas e condutas da organização militar, o que denota a ideia de que a família possa ser uma extensão da corporação, refletida na organização da moradia, do convívio com famílias do mesmo círculo hierárquico do cônjuge militar, na organização do cotidiano (formas de trabalho, lazer etc.), o que indica que a hierarquia transborda os muros dos quartéis e invade a esfera da intimidade dos seus membros.

Mady Segal e outros (2007) se referem às Forças Armadas e à família como instituições gananciosas por exigirem dos seus membros bastante tempo, energia, envolvimento e sacrifício, frequentemente, ao mesmo tempo. Tal percepção é corroborada por Carreiras (1997), que as denominam como instituições vorazes, na medida em que ambas dependem fortemente do investimento dos seus membros e impõem alto nível de exigência como lealdade, tempo e energia.

É dentro desse quadro de referência que se pode situar os desafios para o casal duplacarreira no ambiente militar, pois além de ter que conciliar questões referentes à vida familiar e profissional, incide sobre sua intimidade princípios da hierarquia e da disciplina que conformam o campo das instituições castrenses.

\section{CONCLUSÃo}

A chegada das mulheres na instituição militar promoveu o surgimento de novas relações entre homens e mulheres no meio, não possíveis anteriormente, como o casamento entre pares, e, trouxe consigo, o desafio de conciliação entre a família e a vida militar.

Vale destacar que, por vezes, família e instituições militares se colocam em situação de antagonismo, haja vista que o investimento em uma dessas esferas pode comprometer a atenção dispensada à outra. Se por um lado, em termos profissionais, é vantajoso para o casal serem ambos militares nas ocasiões das transferências (mudança de uma cidade para outra), nos momentos em que devem se dedicar aos cursos de carreira, na maior compreensão mútua das exigências profissionais: horários, escalas de serviço, representações, dentre outros; por outro lado, ter ambos os cônjuges como integrantes de uma instituição com alto nível de exigência profissional, como é o caso das Forças Armadas, pode comprometer e gerar conflitos na dinâmica familiar. 
Os constantes deslocamentos geográficos, a ausência prolongada por ocasiões de exercícios, embarques, missões, serviços são exemplos de situações corriqueiras na carreira dos militares que impactam no cotidiano da família. Em contrapartida, observam-se casos em que o militar abre mão de pleitear comissões importantes para sua carreira em favor da estabilidade do núcleo familiar. Observam-se ainda situações em que militares ajuízam ações na justiça comum, a fim de evitar deslocamentos de cidade, ou mesmo, para mudar-se para cidades com rede de apoio familiar.

Supõe-se que tais embates podem ganhar nuances mais acentuados em casais nos quais ambos são militares, em que valores do militarismo ancorados em princípios da hierarquia e da disciplina podem se fazer presentes na intimidade do casal, cuja pressão em conciliar vida familiar e ocupacional encontra-se presente em ambos os cônjuges.

Estudos com casais de dupla-carreira (DINIZ, 1996, 1999; MARTINS, 2006; PERLIN, 2006; PERLIN; DINIZ, 2005; ROCHA-COUTINHO, 2003) revelam que, independente de trabalharem 0 mesmo número de horas ou mais que seu esposo, e de que a profissão exija tanto ou mais do que a do cônjuge, são as mulheres que pagam o ônus mais alto nos casais que optam por esse estilo de vida conjugal e familiar.

Tal fato encontra-se associado ao acúmulo de jornadas de trabalho por parte das mulheres, na responsabilidade pelo gerenciamento da vida doméstica e na educação e no cuidado com os filhos, no desempenho de múltiplos papéis e funções e no alto nível de exigência pessoal, do cônjuge e da sociedade, que ainda espera que as mulheres invistam na família mais tempo e energia emocional do que o solicitado aos homens.

Torna-se necessário, portanto que pesquisadores se voltem para um fenômeno social importante. Buscou-se, assim, com este artigo, contribuir para a discussão sobre dilemas da interação casamento, trabalho e gênero, especificamente no meio militar, contribuindo, desse modo, com o debate, ainda escasso, sobre a questão.

Ressalta-se, nesse aspecto, que pesquisadores do mundo acadêmico que se propõem a estudar os militares encontram em seu caminho investigativo algumas dificuldades: a começar pela autorização para realização da pesquisa de campo, que segue canais hierárquicos, desconhecidos pelo pesquisador. Obtida tal autorização, enfrentam outros obstáculos: as restrições ao acesso às documentações, bem como resistência e desconfiança de membros da caserna em conceder entrevistas, em relatar experiências, em face do receio de infringir regulamentos, normas, pois temem incorrer em contravenções disciplinares.

Vale ainda destacar como óbice tanto na execução da pesquisa de campo quanto na análise dos conteúdos das entrevistas, a falta de familiaridade por parte do estudioso com o habitus militar, cujo conhecimento é de fundamental importância para decodificação desse universo. 
E foi no sentido de contribuir para reflexão sobre as dificuldades enfrentadas pelos casais dupla-carreira no ambiente militar que se construiu o presente artigo. Através do olhar investigativo endógeno, buscou-se traçar um panorama dos principais aspectos presentes a serem considerados na análise dessa modalidade relacional nas Forças Armadas.

\section{REFERÊNCIAS}

ALMEIDA, M. R. D. Batalhas culturais de gênero: a dinâmica das relações de poder no campo militar naval. 2008. Dissertação (Mestrado em Políticas Sociais) - Universidade Federal Fluminense, Niterói, RJ, 2008.

ARIÈS, P. História social da família e da infância. Rio de Janeiro: Guanabara 1978.

BALTAZAR, M. da S.; SALVADOR, R. Impactos da profissão militar nos padrões familiares: reconfigurações a partir do caso particular do comando de instrução e doutrina. In CONGRESSO PORTUGUÊS DE SOCIOLOGIA, 7., 2012, Porto. Anais... Porto: Universidade do Porto, 2012. Disponível em: http://www.aps.pt/vii_congresso/papers/finais/PAP1500_ed.pdf. Acesso em: 19 jul. 2014.

BIROLI, F. Gênero e Desigualdade: limites da democracia racial. São Paulo: Boitempo, 2018.

BOURDIEU, P.; PASSERON, J. C. A Reprodução: elementos para uma teoria do sistema de ensino. Petrópolis, RJ: Vozes, 2012.

CARREIRAS, Helena. Família, maternidade e profissão militar. Revista Estudos Feministas, Rio de Janeiro, v. 5, n. 1, p. 69, 1997. Disponível em:

https://periodicos.ufsc.br/index.php/ref/article/view/12561/11716. Acesso em: 4 dez. 2013.

CASTELL, M. O fim do patriarcalismo: movimentos sociais, família e sexualidade na era da informação. In CASTELL, M. $O$ poder da identidade. 5. ed. São Paulo: Paz e Terra, 1999. p. 169-286. (A Era da Informação: Economia, Sociedade e Cultura, v. 2).

CASTRO, C. 0 espírito militar: um estudo de antropologia social na Academia Militar das Agulhas Negras. Rio de Janeiro: Ed. Jorge Zahar, 1990.

CHIES, P. V. Identidade de gênero e identidade profissional no campo de trabalho. Revista de Estudos Feministas, Florianópolis, v. 18, n. 2, p. 507-528, 2010. Disponível em: https://periodicos.ufsc.br/index.php/ref/article/view/S0104-026X2010000200013/13664. Acesso em: 10 mai. 2014.

DINIZ, G. Dilemas de trabalho, papel de gênero e matrimônio de casais que trabalham fora em tempo integral. In FÉRES-CARNEIRO, T. Relação amorosa, casamento, separação e terapia de casal. Rio de Janeiro: ANPEPP, 1996. p. 101-111. (Coletâneas da ANPEPP, n. 1). Disponível em: http://www.infocien.org/Interface/Colets/v01n01a10.pdf. Acesso em: 13 maio 2018.

DINIZ, G. Homens e mulheres frente à interação casamento-trabalho: aspectos da realidade brasileira. In FERÉS- CARNEIRO, T. (Org). Casal e família: entre a tradição e a transformação. Rio de Janeiro: NAU, 1999. p. 31-54. 
FORGEAU, F. Les relations hommes/femmes dans les armées à l'épreuve du terrain. [S. I.]:

Centre d’ètudes en sciences de la défese, 2006. (Thématique, n. 3).

FOUCAULT, M. Vigiar e punir: nascimento da prisão. Petrópolis: Editora Vozes, 1987.

GIDDENS, A. A transformação da intimidade. 2. ed. São Paulo: Editora da UNESP, 1993.

HUNTINGTON, S. O Soldado e o Estado: teoria e política das relações entre civis e militares. Rio de Janeiro: Biblioteca do Exército, 1996.

IAMAMOTO, M. V. Renovação e Conservadorismo no Serviço Social: ensaios críticos. São Paulo: Cortez, 1999.

JABLONSKI, B. Atitudes frente à crise do casamento. In FÉREZ-CARNEIRO, T. (Org). Casamento e família: do social à clínica. Rio de Janeiro: NAU, 2001. p. 81-95.

JANOWITZ, M. O soldado profissional: um estudo social e político. Rio de Janeiro: edições GRD, 1967.

LAGRAVE, R.-M. Uma emancipação sob tutela. Educação e trabalho das mulheres no século XX. In DUBY, G.; PERROT, M. (Org). A história das mulheres no Ocidente - século XX. Porto: Ed. Afrontamento, 1995. p. 501-539.

LEIRNER, P. A etnografia como extensão da guerra por outros meios: notas sobre a pesquisa com militares. Mana, Rio de Janeiro, v. 15, n. 1, p. 59-89, 2009. Disponível em:

http://www.scielo.br/pdf/mana/v15n1/03.pdf. Acesso em: 20 mar. 2018.

LEIRNER, P. C. Sobre "nomes de guerra": classificação e terminologia militares. Etnográfica, Lisboa, v. 12, n. 1, p. 195-214, 2006. Disponível em: http://www.scielo.mec.pt/pdf/etn/v12n1/v12n1a10.pdf. Acesso em: 10 jan. 2018.

LOMBARDI, M. R. As mulheres nas forças armadas brasileiras: a Marinha do Brasil. São Paulo: Fundação Carlos Chagas, 2009.

MUSUMECI, L.; SOARES, B. Polícia e gênero: presença feminina nas PMs brasileiras. Boletim de Segurança e Cidadania, Rio de Janeiro, ano 2, n. 4, p. 1-16, 2004.

MARQUES, J.; HIRON, H. O Corpo auxiliar feminino da reserva da Marinha. 1982. Monografia (Curso de Estado-Maior para Oficiais Superiores) - Escola de Guerra Naval, Rio de Janeiro, RJ, 1982.

MARTINS, A. L. de M. Casamento e trabalho: reflexões sob a ótica de gênero e do ciclo vital. 2006. Dissertação (Mestrado em Psicologia) - Universidade de Brasília, Brasília, DF, 2006.

MATHIAS, S. KI. (Org). Sob o signo de Atena: gênero na diplomacia e nas Forças Armadas. São Paulo: Editora UNESP, 2009.

MONTEIRO, A. M. Avanços no estudo da conjugalidade: os casais de dupla carreira. Psicologia: ciência e profissão, Brasília, DF, 2001, v. 21, n. 3, p. 10-19, 2001. Disponível em: http://www.scielo.br/scielo.php?script=sci_arttext\&pid=\$1414-98932001000300003. Acesso em: 11 jul. 2018. 
PERLIN, G. Casamentos contemporâneos: um estudo sobre os impactos da interação famíliatrabalho na satisfação conjugal. 2006. Tese (Doutorado em Psicologia) - Universidade de Brasília, Brasilia, 2006.

PERLIN, G.; DINIZ, G. Casais que trabalham e são felizes: mito ou realidade? Revista de Psicologia Clínica, Rio de Janeiro, v. 17, n. 2, p. 15-29, 2005. Disponível em: http://www.scielo.br/scielo.php?pid=S0103-56652005000200002\&script=sci_abstract\&tlng=pt. Acesso em: 12 fev. 2018.

RAPOPORT, R.; RAPOPORT, R. N. The dual career family: a variant pattern and social change. Human Relations, [S. I.], v. 22, n. 1, p. 3-30, 1969. Disponível em http://hum.sagepub.com/content/22/1/3.extract. Acesso em: 1 out. 2010.

ROCHA-COUTINHO, M. L. Dos contos de fada aos super-heróis: mulheres e homens brasileiros reconfiguram identidades. Revista de Psicologia Clínica, Rio de Janeiro, v. 12, n. 2, p. 65-82, 2000.

ROCHA-COUTINHO, M. L. Quando o executivo é uma "dama": a mulher, a carreira e as relações familiares. In FERES-CARNEIRO, T. (Org.). Família e casal: arranjos e demandas contemporâneas. Rio de Janeiro: Editora PUC-Rio/Loyola, 2003. p. 57-77.

SEGAL, M. W. et al. What we know about army families. [S. I.: s. n.], 2007. Disponível em: http://www.mwrbrandcentral.com/HOMEPAGE/Graphics/Research/whatweknow2007.pdf. Acesso em: 13 jun. 2014.

SILVA, C. R. da. Explorando o "mundo do quartel". In CASTRO, C.; LEIRNER, P. (Org). Antropologia dos militares: reflexões sobre pesquisa de campo. Rio de Janeiro: Editora FGV, 2009. p. 107-127.

SILVA, C. R. da. Famílias de militares: explorando a casa e a caserna no Exército Brasileiro. Revista de Estudos Feministas, Florianópolis, v. 21, n. 3, p. 861-882, 2013. Disponível em: http://www.scielo.br/pdf/ref/v21n3/06.pdf. Acesso em: 10 jun. 2014.

THERBORN, G. Sexo e poder: a família no mundo 1900-2000. São Paulo: Contexto, 2006.

VAITSMAN, J. Flexíveis e plurais: identidade, casamento e família em condições pós-modernas. Rio de Janeiro: Rocco, 1994.

\section{Notas}

1 Tomando a contribuição de Huntington (1996, p. 172), "[...] a oficialidade é o elemento dirigente ativo da estrutura militar e é o responsável pela segurança militar na sociedade"; já a praça constitui em elo entre o comando e a tropa, significa dizer que não exerce função dirigente e, sim, de comando de tropa, e está em contato direto com o extrato mais baixo da hierarquia militar.

2 Therborn (2006, p. 29) diz: "O patriarcado tem duas dimensões intrínsecas básicas: a dominação do pai e a dominação do marido, nessa ordem. Em outras palavras. 0 patriarcado refere-se às relações familiares, de geração ou conjugais - ou seja, de modo mais claro, às relações de geração e de gênero". Castell (1999, p. 169) complementa: "[...] relacionamentos interpessoais e, consequentemente, a personalidade, também são marcados pela dominação e violência que têm sua origem na cultura e instituições do patriarcalismo".

3 Dentre as forças militares auxiliares brasileiras, coube à Polícia Militar do Estado de São Paulo (PMESP) o pioneirismo deste processo. O Estado de São Paulo instituiu em 1959 um corpo feminino de guardas civis e o incorporou em 1970 aos 
quadros da então recém-criada PMESP. (MUSUMECI; SOARES, 2004). Algumas destas mulheres militares integraram as equipes responsáveis pela formação da primeira turma de mulheres militares da MB. (ALMEIDA, 2008).

${ }^{4}$ A primeira turma feminina era composta por 201 oficiais e 311 praças; desse montante $75 \%$ foram distribuídas para trabalhar no HNMD. 